\title{
Using apparatus with vortex layer of ferromagnetic particles for production of unburnt synthanite
}

\author{
Alexander Kaklyugin ${ }^{1, *}$, Inna Trishchenko ${ }^{1}$, Alexander Kozlov ${ }^{1}$, and Lyubov Kastornykh ${ }^{1}$ \\ ${ }^{1}$ Don State Technical University, \\ 162, Sotsialisticheskaya St., Rostov-on-Don, 344022, Russian Federation
}

\begin{abstract}
Here is offered a method of production of unburnt synthanite from natural minerals using apparatus with vortex layer of ferromagnetic particles. There was fulfilled comparative quality analyses of anhydrite binding substances, produced by anhydrite rock milling together with complex solidifying activator in traditional ball mills, and substances produced by our method. It was stated that achieved rising of the hydration activity of synthanite by collective milling of the raw material components was a result of ferromagnetic particles hindered impact under magnetic field influence. The reason for such activity is not only increase in specific surface area of the milling material, but changes in anhydrite structure at the crystalline grid level, preserving a lot of defects on the separate particle surface.
\end{abstract}

\section{Introduction}

Russian gypsum industry now is in a very difficult situation. It faces a number of rather serious problems [1]:

- decrease in sales volume and production of most popular materials - gypsum boards and gypsum fiber sheets;

- constant rising of production expenses with simultaneous price reduction;

- worsening of producer's technical and economic performance because of purchasing power reduction, followed by demand removing into cheap production segment.

At the same time it is noted that there's no background for fundamental change in the near future; we can't expect consumption rise in the industry as well as profits growth in production and sales. It's unlikely that new manufacturing sites will be built, but low-gain business will close inevitably. In such situation operating business needs maximum effort concentration on using resources at disposal, putting to use free sites and facilities, resource-saving and sustainable measures. That's why processing of anhydrite rock (waste product of gypsum rock production) with the aim of unburnt synthanite production and further wall stone production may be considered now rather promising. This path meets the requirements of the best available methods [2,3[. Cost-benefit analyses proved that to put it into life is worthwhile when technology uses existing manufacturing area [4].

\footnotetext{
Corresponding author: kaklugin@gmail.com
} 
Modernization will result in additional range of production popular low cost items and growth of technical and economic features of the enterprise.

Synthanite was widely used in the end of XIX - beginning of the XX centuries for brickwork and plaster mortars and for wall stone production [5]. Increasing volume of production of fast hardening low temperature calcined gypsum binder forced synthanite out of the building market. It is forgotten now, building industrial enterprises don't produce it. But more and more people are interested in synthanite. Some scientists are working out more perfect technology of synthanites production and usage. The results are being patented and published [6, 7 etc.], discussed at different conferences.

Personnel of the Don State Technical University in their complex studies research possibility and effect of anhydrite rock recycling. Economical and ecological viability of wall stone production based on unburnt synthanite as well as its technical realization are proved $[8,9]$. It should be mentioned that not all results of investigation were published. Thus one investigation was devoted to production of unburnt synthanite with technical characteristics close to high temperature burnt binder. The hypothesis checked was: application of apparatus with vortex layer of ferromagnetic particles, with hindered impact on grind natural anhydrite rock and changing the substance structure at the crystalline grid level, will allow to produce unburnt synthanite with high hydration activity. This will be achieved not only because of the increase in specific surface area, but presence of multiple defects on the separate particle's surface.

Results confirming this hypothesis are given below. They also show that this direction of scientific research is actual and practical.

Synthanite can be produced from natural gypsum or anhydrite rock as well as from chemical industry-related waste, containing anhydrous calcium sulfate. Depending on the way of production, synthanites are divided into high-temperature burnt and unburnt [5]. In the first case binding material is obtained by grinding burnt at the temperature $600-700{ }^{\circ} \mathrm{C}$ gypsum rock. In the second case - by milling in different mills natural anhydrite, or activation of industry-related waste that needs no grinding.

Synthanite produced by natural materials burning, compared with unburnt has higher quality. Russian government technical requirements stated brand marks for synthanite: 50 , 100, 150 and 200. Brand 50 was used only for binder produced from natural anhydrite. Production of unburnt synthanite with higher characteristics is possible when its activity is increased.

Anhydrite hydration activity is increased by higher degree of grinding and (or) adding hardening activator. Main role in hardening process plays particles surface condition, which depends on the nature and concentration of active surface centres [10]. While grinding natural anhydrous calcium sulfate, some chemical binds brake and form on particles surfaces non-saturated cations $\mathrm{Ca}^{2+}$ and anion tetrahedral groups $\mathrm{SO}_{4}^{2-}$. Newly formed mineral particles surface is highly reactive.

To accelerate hardening, milling equipment with impact crushing of material should be used. In contrast with abrading mills, where milling produces increase of specific surface area of processed material, under impact force structure changes at crystalline grid level occur (chemical binds break, phase change, multiple structure defects appear, solid phase reactions accelerate etc.). This results in increased hydration activity of produced binding material [10-13].

In building materials industry mills can be divided into three groups depending on the method of obtaining dispersing stress: with mechanical, aerodynamic and electromagnetic way of energy transition to processed material particles. 
In the first group there are traditionally used ball, rod, vibration and planetary mills. They are characterized by design complexity, high metal and energy consumption, low productivity, being a source of much noise and dust.

Different fluid mills represent the second group of braking machines. Among their advantages are high efficiency with fast material processing, no wearing pieces, possibility to combine milling with other processes (for example, drying). But these mills require great power for stable aerodynamic operation mode. Granulometry of milling material has high polydispersity, and this gives negative impact on hydration behavior of the resulting binder. Thus, with narrow granulometry hydration of binding particles happens more homogeneously, with the same speed. This as a result accelerates processes of binding materials hardening, including anhydrite [11].

Representatives of the third group of mills are new, but well proved themselves. Electromagnetic mills and apparatus with vortex layer of ferromagnetic particles belong to this type of equipment. They guarantee high power density of milling, enable shortening of raw material processing time, increased dispersion degree of binder, with power consumption reduction at the same time.

\section{Methods}

Personnel of the Don State Technical University, Building Materials department have studied unburnt synthanite, produced by alternative methods of raw material milling:

- high milling in the ball mill during several hours;

- short -time (several minutes) grinding in apparatus with vortex layer of ferromagnetic particles.

As a raw material was taken natural anhydrite rock, not used for gypsum binders production because of low percent of calcium sulfate dehydrate. For hardening activator was used drowned nonhydraulic lime and silica material in quantities 5 and $15 \%$ of anhydrite rock mass respectively.

Dispersity of produced synthanite was estimated by specific surface area parameter, using PCH-11M(SP) device.

Cylinders of $5.05 \mathrm{~cm}$ in diameter and the same height were made from produced synthanite. They were formed of harsh mixture with water percentage equals 9 by pressing in special moulds under $40 \mathrm{MPa}$ pressure. After 28 days of hardening under the normal conditions the cylinder samples were dried and tested.

\section{Results}

The results of estimating specific surface area of synthanites produced by different methods are given in Tables 1 and 2 .

Table 1. Dependence of binder specific surface area from raw material milling time in a ball mill.

\begin{tabular}{|c|c|c|c|c|}
\hline \multirow{2}{*}{$\begin{array}{c}\text { Milling time, } \\
\text { hours }\end{array}$} & \multicolumn{2}{|c|}{ Sieve residue, $\%$} & \multirow{2}{*}{$\begin{array}{l}\text { Passed through the } \\
\text { sieve № } 008, \%\end{array}$} & \multirow{2}{*}{$\begin{array}{c}\text { Specific surface } \\
\text { area, } \mathrm{cm}^{2} / \mathrm{g}\end{array}$} \\
\hline & № 02 & № 008 & & \\
\hline 1 & 19.6 & 13.5 & 66.9 & 2171 \\
\hline 2 & 7.3 & 6.7 & 86.0 & 4142 \\
\hline 3 & 1.5 & 3.1 & 95.4 & 4760 \\
\hline 4 & 1.2 & 2.5 & 96.3 & 5560 \\
\hline 5 & 0.8 & 2.0 & 97.2 & 6007 \\
\hline 6 & 0.9 & 2.4 & 96.7 & 6222 \\
\hline 7 & 0.9 & 3.1 & 96.0 & 6650 \\
\hline 8 & 1.2 & 6.8 & 92.0 & 6808 \\
\hline
\end{tabular}


Table 2. Dependence of binder specific surface area from raw material milling time in apparatus with vortex layer of ferromagnetic particles.

\begin{tabular}{|c|c|c|c|c|}
\hline \multirow{2}{*}{$\begin{array}{c}\text { Milling time, } \\
\text { seconds }\end{array}$} & \multicolumn{2}{|c|}{ Sieve residue, \% } & $\begin{array}{c}\text { Passed through the } \\
\text { sieve № 008, \% }\end{array}$ & $\begin{array}{c}\text { Specific surface } \\
\text { area, } \mathrm{cm}^{2} / \mathrm{g}\end{array}$ \\
\hline 30 & № 02 & № 008 & 69.2 & 2615 \\
\hline 75 & 18.1 & 12.7 & 93.6 & 3955 \\
\hline 120 & 2.7 & 3.7 & 95.3 & 4545 \\
\hline 165 & 1.5 & 3.2 & 96.5 & 5183 \\
\hline 210 & 0.8 & 2.3 & 97.2 & 6085 \\
\hline 255 & 0.7 & 1.8 & 97.5 & 6555 \\
\hline 300 & 0.3 & 1.7 & 98.0 & 7015 \\
\hline
\end{tabular}

It is known that after achieving some optimum value of milling fineness, found experimentally, potential energy of the particles surface rises considerably [12]. This leads to their aggregation, followed by binder qualities worsening. Analyzing the results of the experiments, it became possible to state that efficiency of anhydrite rock milling in the ball mill decreases, when milling lasts longer than five hours. It should be also kept in mind that high milling fineness is accompanied by considerable growth of mechanical and electrical energy consumption. So we can conclude that milling longer than five hours is not practical. Milling time of producing synthanite with equivalent specific surface area in apparatus with vortex layer of ferromagnetic particles and in ball mills found to be incomparable. For example, to get binder specific surface area $\sim 6000 \mathrm{~cm}^{2} / \mathrm{g}$ apparatus with vortex layer of ferromagnetic particles needs about $3.5 \mathrm{~min}$, while in a ball mill it takes 5 hours. It must be also mentioned that in the apparatus with vortex layer of ferromagnetic particles grinding is a result of hindered impact of two ferromagnetic particles. Specific capacity in the impact points rises dramatically and pressure values may reach thousands of megapascals. Such conditions lead to crystalline grid deformation, sharp increase in free energy of substance, followed by rising chemical activity. Electromagnetic field influences significantly activity of processed with vortex layer substance. Authors of works [12-15] have proved that magnetic and electric fields influence both - physical properties of material and chemical reaction rate. Collective investigations made by personnel of Kurchatov institute and Moscow State university named after Lomonosov proved that while grinding non magnetic materials under magnetic field influence, there appear crack nuclei, which can't disappear because of repulsive interaction of crack edges [14]. This means that magnetic field provides structure defects preservation, thus leading to growth of reacting power in binder and prevents separate particles aggregation during grinding.

It can be concluded that high frequency impact force, applied for small contact surfaces of ferromagnetic elements, under the rotating magnetic field influence leads to results exceeding those, produced by materials dispersion in traditional mills [12].

Particles of binding substance, grinded in vortex layer must have high energy, thus activating hydration process. This hypothesis was proved by results of breaking strength tests in the control cylinder samples group. The samples were made of unburnt synthanite produced in a ball mill and in the apparatus with vortex layer of ferromagnetic particles (Figure 1). It was noticed that with the binder specific surface area growth in both cases is observed increase of ultimate compressive strength of artificial rock. Accordingly, with specific surface area growth from 2615 to $6085 \mathrm{~cm}^{2 /} / \mathrm{g}$ in the binder produced by apparatus with vortex layer of ferromagnetic particles, ultimate compression strength rises from 40.3 to $65.6 \mathrm{MPa}$. Binder produced in the ball mill with comparable specific surface area (2171 $6007 \mathrm{~cm}^{2} / \mathrm{g}$ ) gives smaller changes in ultimate compression strength (from 26.1 to 33.6 $\mathrm{MPa}$ ). Therefore, conclusion proving the hypothesis, formulated earlier, is made. Usage of 
modern impact force milling equipment enables production of unburnt synthanite with increased activity.

\section{Discussion}

Applying apparatus with vortex layer of ferromagnetic particles for further development and perfection of synthanite production technologies may be considered to be a rational and true trend. This kind of anhydrite grinding provides industry with binding material of increased activity. Extra advantages of anhydrate rock grinding in apparatus with vortex layer of ferromagnetic particles are: low power consumption and short grinding time.

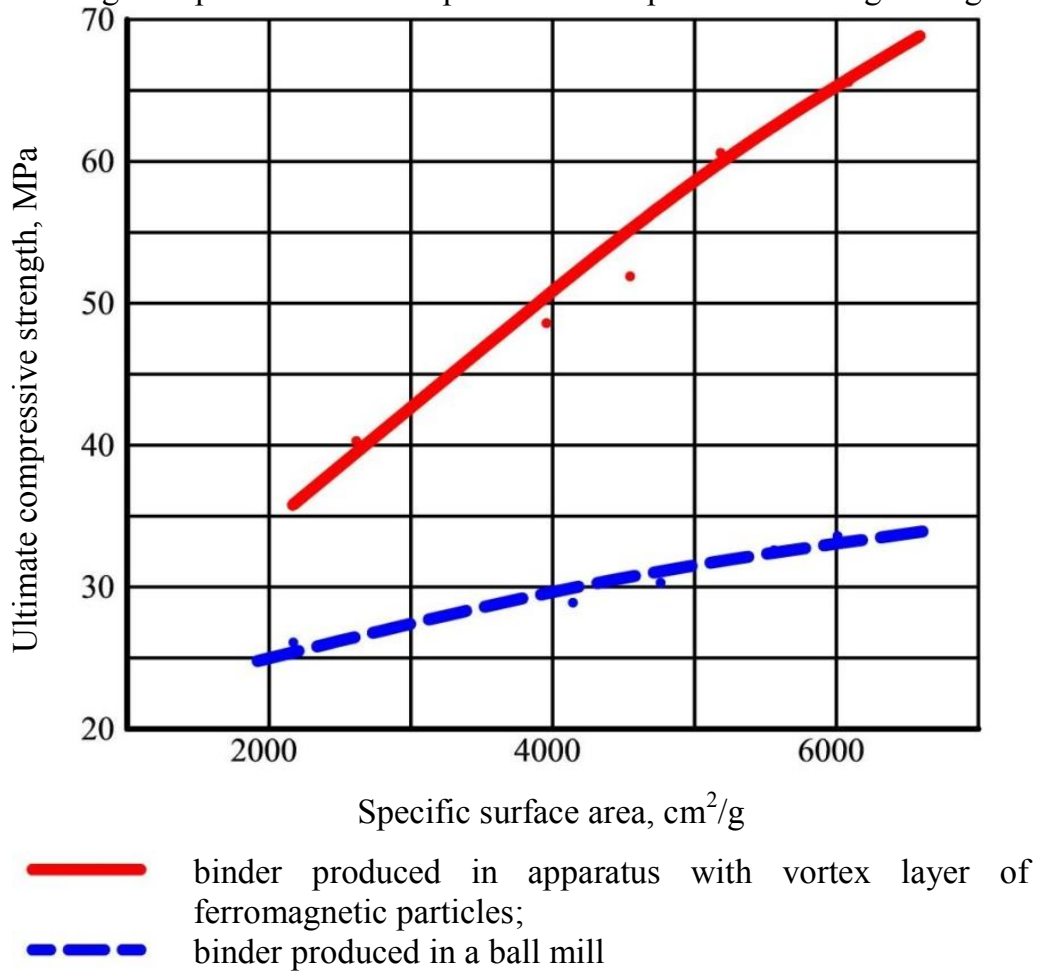

Fig. 1. Correspondence between controlled samples ultimate compressive strength and synthanite specific surface area.

On achieving this technical effect, at the same time the problem is being solved of replenishment raw materials supply for gypsum binder production and building materials manufacturing, based on gypsum binder. As can be seen from the above, it is rational to process natural anhydrite rock not used for gypsum binder production (because of calcium sulfate dihydrate low level) for unburnt synthanite manufacturing. It can be basic material for wall stones (dividing and inside walls). For wider use of such materials further investigations of the ways to increase water resistance properties of artificial rock, based on studied synthanite, are necessary.

\section{References}

1. Gypsum material market tendencies 2017: results and forecasts (interview with J.Goncharov), link: http://www.rosgips.ru/en/news/185-tendentsii-rynka-gipsovykhmaterialov-2017-itogi-i-prognozy-intervyu-s-goncharovym-yu-a; $\underline{05.05 .2018}$ 
2. T. Guseva, J. Molchanova, A. Mironov, A. Malkov, Competence, 8, 4-7 (2015)

3. A. Kaklyugin, I. Trishchenko, Building and Architecture-2017, Civil Engineering Faculty: sci.-prac. conf. materials DSTU, 185-191 (2017)

4. I. Trishchenko, A. Kaklyugin, Building and Architecture-2017, Civil Engineering Faculty: sci.-prac. conf. materials DSTU, 180-185 (2017)

5. G. Airapetov, Building materials, reference book (Phenix, Rostov-on-Don, 2009)

6. S. Bondarenko, B. Trofimov, T. Chernih, Building expert, 2007, link http://expert74.com/nomer.php?art=181, 10.11.2014

7. A. Kaklyugin, I. Trishchenko, A. Kozlov, M. Mirskaya, Izvestiia vuzov. Stroitel'stvo, 6, 23-29 (2013)

8. RF patent 2566154, Processing line for preparing unfired anhydrite binder, $\mathrm{M}$. Mirskaya, A. Kaklyugin, I. Trishchenko, application № 2014110985/03, applied by Rostov State University of Civil Engineering, 21.03.2014, published 20.10.2015 bul. № 29

9. A. Kaklyugin, I. Trishchenko, A. Kozlov, A. Chizhov, Izvestiya vuzov. Investitsii. Stroitelstvo. Nedvizhimost, 3, 70-77 (2016)

10. L. Svatovskaya, M. Sichjov, Activated cement hardening (L, Stroyizdat, 1983)

11. M. Garkavi, A. Artamonov, E. Kolodjazhnaya, A. Burjanov, Stroitel'nye materialy, 7, 16-18 (2014)

12. D. Logvinenko, O. Sheljakov, Intencification of technological processes in apparatus with vortex layer (Technika publisher, Kiev, 1976)

13. V. Regel, A. Slutsker, E. Tomashevski, Kinetic nature of solid bodies' strength (Moscow, Nauka, 1974)

14. P. Alexandrov, V. Budragin, M. Shahov, N. Nikanorova, E. Trofimchuk, Voprosy atomnoi nauki i techniki, Thermonuclear fusion, 1, 24-30 (2005)

15.Z. Morgunov, UFN, 174 (2), 131-152 (2004) 